\title{
CV-Muzar - uma comunidade virtual utilizando tecnologias de IA para auxiliar na formação de sub-comunidades
}

\author{
Cristiane Durigon Testa - CCC/UPF - cristiane_dt@yahoo.com.br \\ Ana Carolina Bertoletti De Marchi - CCC/UPF - carolina@upf.br
}

\begin{abstract}
Resumo: A CV-Muzar é a comunidade virtual do Muzar da UPF, voltada para a discussão sobre ciências naturais e museologia. Além das ferramentas clássicas de uma comunidade virtual, a CV-Muzar conta com uma camada inteligente, ou seja, um módulo de formação de grupos auxiliado por um Sistema Multiagente (SMA) que tem como principal finalidade buscar informações de participantes que possuam semelhança de interesse e complementaridade de conhecimento para formar novos grupos de discussões mais pontuais. Desta forma, o SMA objetiva filtrar informações de grupos e membros da comunidade e enviar convites para que os participantes se encontrem em grupos de assuntos afins. Neste sentido, este artigo irá apresentar características importantes sobre formação de grupos e o SMA desenvolvido.
\end{abstract}

Palavras-chave: comunidades virtuais, agentes inteligentes, sistemas multiagentes.

\section{CV-Muzar - the virtual community to use IA technologies for support the sub- communities build}

Abstract: The CV-Muzar is a virtual community of the Museum Zoobotânico Augusto Ruschi the University of Step fund, dedicated to the discussion on natural sciences and museology. In addition to the traditional tools of a virtual communities, the CV-Muzar account with a layer intelligent, or a training module of groups aided by a system Multiagent (SMA), which has as main purpose fetch information from participants who possess similarity of interest and complementarity of knowledge to form new groups of more focused discussions. Thus, the SMA's main function filter information from groups and participants and send invitations to the participants are in groups of related issues. The goal of this paper is to present behaviors of groups aides and the SMA development.

Keywords: virtual communities, intelligence artificial, MultiAgent Systems.

\section{Introdução}

Os avanços tecnológicos e sociais constantes intensificaram o uso de diferentes formas de interação entre as pessoas, acarretando na formação de grupos que visam, entre outros, discutir assuntos de interesse em comum. Esses grupos sociais mediados por computadores são conhecidos como Comunidades Virtuais (CVs). Nas CVs as pessoas se comunicam, síncrona ou assincronamente, promovendo discussões intelectuais, 
trocando conhecimento, compartilhando suporte emocional, fazendo planos, procurando amigos e promovendo meios alternativos de aprendizagem.

Atualmente, uma das principais preocupações dentro das CVs é possibilitar discussões mais pontuais em grupos menores, que propiciem a junção de diferentes visões sobre o contexto da discussão, de modo a auxiliar na realização de atividades complexas que necessitam de cooperação e colaboração para a resolução.

Essa necessidade urgente pela redução do número de participantes em grupos mediados por recursos tecnológicos também foi objeto de estudo na CV-Muzar (Comunidade Virtual Museu Zoobotânico Augusto Ruschi da Universidade de Passo Fundo). Durante os quase três anos de utilização, identificou-se na CV-Muzar a necessidade de reunir participantes com semelhanças de interesses e complementaridade de conhecimento.

Para auxiliar tal formação, automatizando tarefas e reduzindo as atividades do coordenador do grupo, foi desenvolvido um Sistema Multiagente (SMA) que filtra as informações dos grupos e dos participantes e analisa perfis que se assemelham, de modo a integrar os participantes aos grupos existentes. O SMA foi utilizado por se tratar de uma tecnologia de colaboração, que permite a fácil adequação às nossas necessidades e por se basear no comportamento social, dando ênfase a interações de suas entidades (Wooldridge 2002). Com isso, acreditamos ser possível aumentar as interações e, assim, amenizar a falta do contato face-a-face presente em ambientes virtuais.

Diante do contexto acima descrito, este artigo tem como objetivo apresentar brevemente a CV-Muzar e descrever detalhadamente o Sistema Multiagente responsável pela criação das sub-comunidades.

\section{Comunidade Virtual do Muzar (CV-Muzar)}

A CV-Muzar ${ }^{1}$ (Figura 1) é uma comunidade virtual desenvolvida especificamente para o Museu Zoobotânico Augusto Ruschi (Muzar) da Universidade de Passo Fundo (De Marchi 2006). A idéia principal da CV-Muzar é aproximar pessoas que tenham interesse em ciências naturais e museologia, além de todo o público visitante do museu.

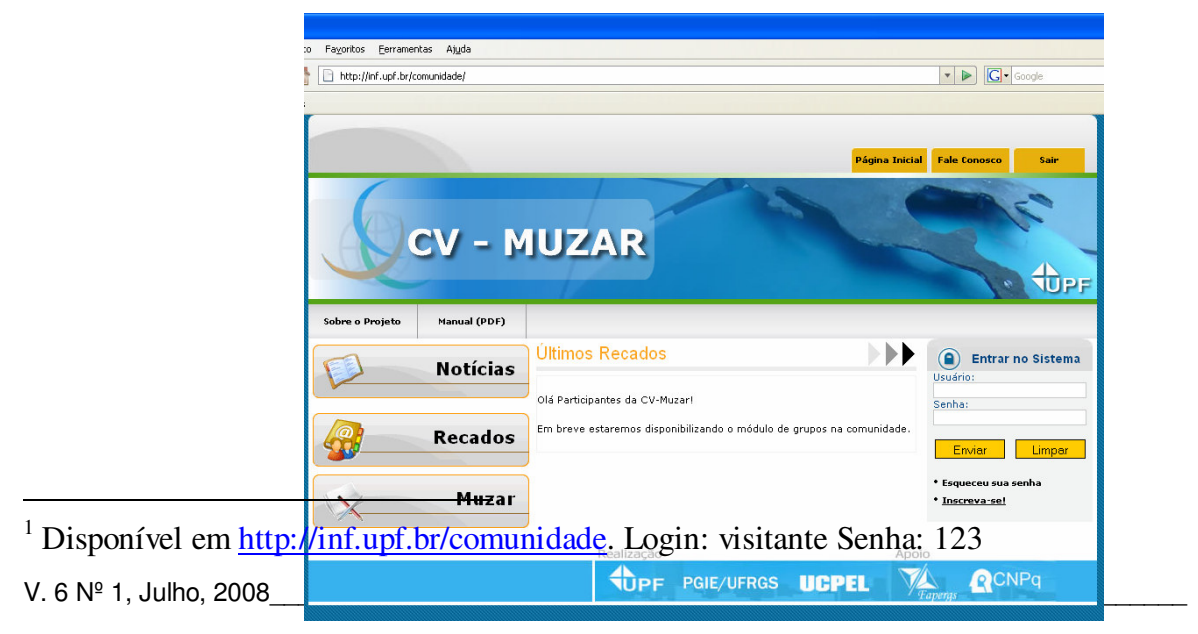


Para o desenvolvimento da CV-Muzar fizemos uso dos conceitos de comunidades virtuais para promover as trocas entre os visitantes e os objetos de aprendizagem (OAs). Os OAs favorecem a expansão comunicativa do museu, uma vez que possibilitam a criação de materiais didáticos simples, pequenos e que podem ser facilmente utilizados fora do ambiente do museu.

O ambiente possui um amplo acervo de informações construído ao longo de quase três anos de utilização. As informações disponíveis são objetos de aprendizagem (OAs) que compreendem materiais desenvolvidos para as exposições, materiais contidos no Museu e produções dos usuários. Devido às produções constantes, o ambiente está em permanente atualização e crescimento.

Para a construção dos elementos básicos do ambiente partimos do pressuposto que a essência de um museu é a aprendizagem informal. Nosso objetivo é que o ambiente favoreça a aprendizagem ao longo da vida, de uma forma casual e espontânea, sem a existência de uma estrutura rígida e curricular. O objetivo é criar laços mais fortes entre os participantes, os aproximando.

O objetivo da formação de grupos na CV-Muzar partiu da realização da primeira experimentação do ambiente, onde os participantes relataram a necessidade de um local onde pudessem trocar idéias sobre assuntos específicos da sua área de conhecimento. Com isso, elaboramos um protótipo de como seria o desenvolvimento desses grupos e que tecnologia poderíamos utilizar para auxiliar a construção desse novo módulo.

Após algum tempo de pesquisas e com base em outros ambientes virtuais de aprendizagem que já tinham o módulo de formação de grupos, analisamos as necessidade apontadas pelos participantes da CV-Muzar e constamos que os grupos deveriam ser formados por duas necessidades básicas: semelhança de interesse e complementaridade de conhecimento. Estas necessidades são apresentadas na seção 3 com maiores detalhes.

\section{Formação de Grupos e sua Importância em CV}

A formação de grupos na área educacional vem sendo estuda desde a década de 40, quando pesquisadores examinaram grupos a partir do comportamento de seus membros (Barker e Barker 2001). Alguns anos mais tarde, Vygotsky (1987) apresentou sua teoria de formação de grupos, a qual tomou um impulso maior por basear-se na experiência de que através da discussão há uma consolidação do conhecimento e a descoberta de novas soluções. 
Na mesma época que Vygostsky apresentava sua teoria, a Indústria Japonesa já se beneficiava com a utilização de grupos para agilizar no desenvolvimento de tarefas. Desde então, os grupos são formados para os mais diversos tipos de tarefas, entre elas, as tarefas educacionais.

Esse mesmo conceito de formação de grupos do ensino tradicional foi agregado ao ensino à distância, onde já é possível constatar alguns indícios de que a formação de grupos em AVAs proporciona maior troca de conhecimento e aproximação entre os participantes inseridos no ambiente, principalmente porque integra participantes com interesses comuns.

Os grupos da CV-Muzar são chamados de sub-comunidades. Eles são criados a partir de dois conceitos fundamentais:

- semelhança de interesse: formado por participantes que possuam perfis semelhantes;

- complementaridade de conhecimento: formado por participantes que estão reunidos para realizar tarefas complexas as quais exigem a composição de habilidades para a resolução dos problemas.

A formação das sub-comunidades é realizada através de uma camada inteligente implementada sob a CV-Muzar, que resulta no envio de convites de participação aos integrantes da comunidade. Esta camada inteligente é composta por um sistema multiagente que será apresentado na próxima seção.

\section{A Processo de Formação das Sub-Comunidades}

Para a formação das sub-comunidades foi preciso reunir três elementos:

- perfil do participante: obtido através de um formulário preenchido no momento da inscrição (Figura 2). O participante informa suas áreas de interesses, comentários sobre o que mais gosta, palavras-chave, entre outras. Essas informações são mantidas no banco de dados para que o SMA as utilize para aproximar os participantes dos grupos, como será apresentado posteriormente.

- criação de grupos: qualquer participante ativo na CV-Muzar pode criar um novo grupo, porém com uma ressalva, que não exista nenhum grupo já criado com os mesmos objetivos de discussões. Desta forma, o participante criador do novo grupo ganha o status de coordenador do grupo, ficando responsável por preencher um pequeno descritor informando as características do grupo, como pode ser observado na Figura 3.

- sistema multiagente: formado com a união dos dois elementos acima descritos, conforme detalhado na próxima seção.
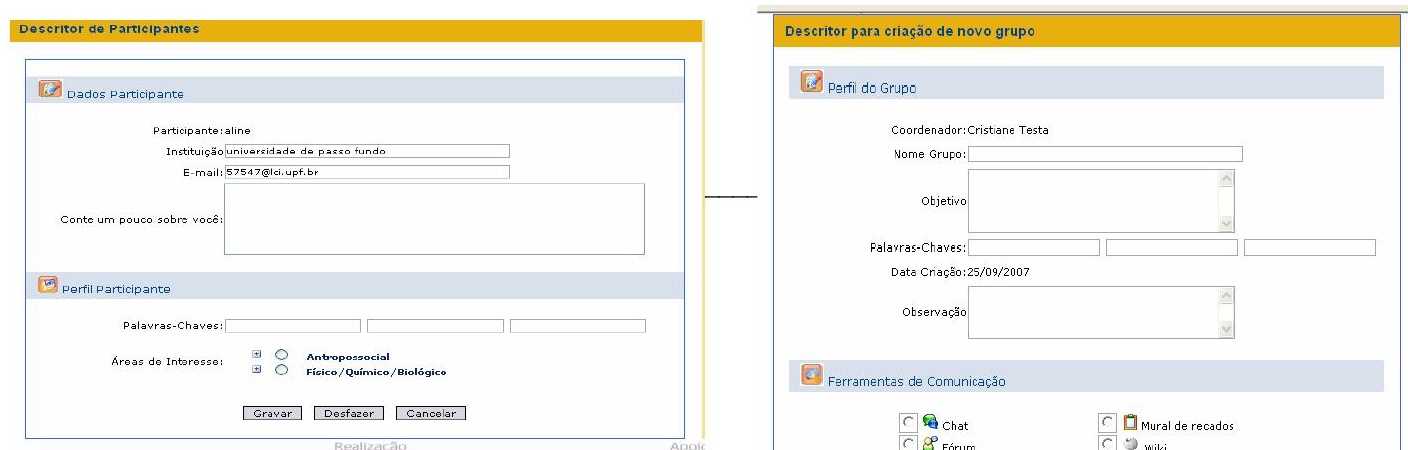


\subsection{Desenvolvimento do Sistema Multiagente}

O desenvolvimento do Sistema Multiagente para a formação das sub-comunidades se dá através da criação de duas sociedades: estática e dinâmica.

A sociedade estática é denominada Sociedade Investigadora de Sub-Comunidade (SIS-C) e tem como objetivo investigar as informações sobre os grupos. As funções dos agentes que a compõem são pré-definidas. Estes, por sua vez, não precisam ser autônomos, pois com o passar do tempo o repositório de conhecimentos poderá se aperfeiçoar.

Para a sociedade SIS-C foram definidas algumas características como, por exemplo, a eleição de um agente líder, já que na sociedade do tipo estática os papéis são definidos. $\mathrm{O}$ agente líder é escolhido aleatoriamente, não dependendo do seu histórico de conhecimento. A tarefa do agente líder é repassar as tarefas requisitadas pelo ambiente aos demais agentes da sociedade. O processo de divisão de tarefas inicia-se quando o agente líder recebe a informação de que um novo grupo foi criado. Nesse momento, tal agente deve investigar o perfil informado e consultar a tabela de agentes para verificar quais agentes têm a capacidade de atender a requisição do perfil do grupo. Na tabela, o agente líder encontra informações como, por exemplo, a capacidade do agente Ag1 de desenvolver a tarefa proposta "T1". O agente líder pergunta, então, ao agente Ag1 se está disponível para atender a requisição (Figura 4). Em caso afirmativo, há uma comunicação direta entre o agente requisitante e o prestador de serviço. A opção de usar um agente líder possibilita a interoperabilidade entre os agentes heterogêneos que compõem a sociedade. As tarefas que devem ser executadas pelos agentes na sociedade SIS-C estão apresentadas na Tabela 1.

Tabela 1 - Tarefas executadas pelos agentes na sociedade SIS-C

\begin{tabular}{l|l} 
Tarefa & Descrição
\end{tabular}




\begin{tabular}{l|l}
\hline & $\begin{array}{l}\text { - verifica todas as informações disponibilizadas pelo coordenador do grupo; } \\
\text { - verifica se o perfil proposto não é igual a algum outro grupo; } \\
\text { - verifica se o tema principal do grupo está de acordo com a idéia central do } \\
\text { ambiente que é ciências naturais. }\end{array}$ \\
$\begin{array}{l}\text { 1. Busca pelo perfil } \\
\text { do grupo }\end{array}$ & $\begin{array}{l}\text { Se todos os requisitos estiverem de acordo, as demais atividades são realizadas; } \\
\text { devem ser revisados. }\end{array}$ \\
\hline $\begin{array}{l}\text { 2. Busca por área de } \\
\text { concentração }\end{array}$ & $\begin{array}{l}\text { - recebe mensagem da tarefa 1 informando que a tarefa foi cumprida e o grupo } \\
\text { está com as características completas; } \\
\text { - busca pela área de concentração; } \\
\text { - recebe as informações encontradas e armazena. }\end{array}$ \\
\hline $\begin{array}{l}\text { 3. Busca pela área de } \\
\text { interesse }\end{array}$ & $\begin{array}{l}\text { - recebe mensagem da tarefa 1. Se tarefa cumprida, efetua a busca pela área de } \\
\text { interesse e armazena informação. }\end{array}$ \\
\hline $\begin{array}{l}\text { 4. Armazena } \\
\text { informações }\end{array}$ & $\begin{array}{l}\text { - armazena todas as informações pesquisadas para fazer a busca por participantes } \\
\text { que possuam semelhança de interesse ou competência para participar do novo } \\
\text { grupo. }\end{array}$ \\
\hline
\end{tabular}

Para facilitar a compreensão do processo, será exemplificado agora a criação de uma sub-comunidade. O participante "A" tem o desejo de criar uma nova subcomunidade com as seguintes características: Nome do grupo = Poluição da Água; Área de concentração = Biologia; e Áreas de interesse $=$ danos à saúde, problemas de saneamento.

Neste momento, a sociedade SIS-C inicia o seu trabalho de busca por informações, estabelecendo um canal com a sociedade. Após, é realizada a avaliação da execução das tarefas definidas pelo agente líder aos demais agentes. Caso a avaliação da tarefa seja aceita, a mesma é realizada. Senão, a tarefa recebe o status de rejeição por falta de disponibilidade dos agentes que possuem competência para a execução. Por fim, as informações necessárias sobre os grupos, para a posterior busca por participantes, são armazenadas.

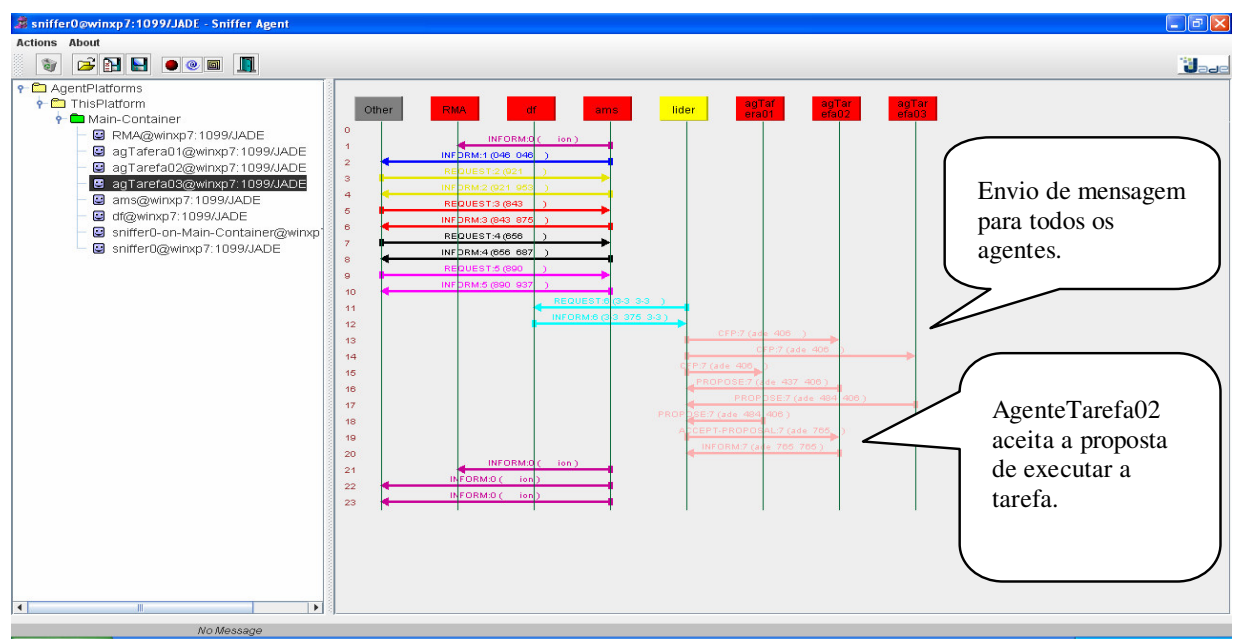


CINTED-UFRGS Novas Tecnologias na Educação

Figura 4. Comunicação entre os agentes na sociedade SIS-C

Após terminar o ciclo de comunicação da sociedade SIS-C, o processo de verificação de novos grupos e a atualização dos dados dos grupos já existentes, tem-se uma nova base de informações detalhada sobre os grupos e quais os tipos de participantes devem ser procurados para serem convidados a participar. Com os dados dos grupos disponíveis, é preciso obter as informações sobre os participantes para concretizar a formação das sub-comunidades.

Neste momento, a Sociedade Investigadora de Participantes (SIP) inicia sua execução. A SIP tem como objetivo recuperar as informações armazenadas pela SIS-C e, com base nelas, buscar participantes que tenham interesse nos assuntos dos grupos criados ou que possam contribuir de alguma forma para a concretização dos mesmos. Ao encontrar possíveis participantes, automaticamente é enviado um convite de participação, que pode ou não ser aceito pelos receptores.

Tal sociedade é classificada como dinâmica pelo fato que neste tipo de organização existe a necessidade da interação social, ou seja, os agentes devem conseguir se agrupar e interagir a fim de alcançar seus objetivos locais, cuja combinação eventualmente resulte na solução do objetivo global da comunidade.

Dentre os modelos descritos de organizações dinâmicas existentes, optamos por utilizar as Coalisões Baseadas em Dependência (CBD), pelo fato de que a execução das tarefas ocorre através da cooperação dos agentes para alcançar um determinado objetivo. Este modelo de organização é baseado na Teoria do Poder Social, que utiliza o conceito de relações de dependência. Nesta organização, antes de propor uma coalisão a qualquer agente, são analisadas as relações de dependência que existem entre o agente e os outros componentes da sociedade.

Neste sentido, podemos fazer uma prévia relação de como seria a escolha do parceiro do agente da sociedade SIS-C com um agente da sociedade SIP, onde este oferecerá uma maior possibilidade de cooperação. A formação de coalisões no modelo CBD se passa do seguinte modo (Sichman, 1995):

-Escolha de um objetivo: um agente Ag1 escolhe um determinado objetivo a atingir, dentre aqueles que constam em sua descrição externa (SIS-C). Tal escolha é guiada pela noção de objetivos atingíveis. Caso não existam mais objetivos a atingir, o agente $\mathrm{Ag} 1$ não tenta mais formar coalisões.

- Escolha de um plano: supondo que Ag1 tenha escolhido o objetivo G1, o próximo passo é que seja escolhido um plano para que se possa atingi-lo. Como o agente pode ter mais de um plano para o mesmo objetivo, a escolha do plano baseia-se na noção de plano factível. Caso não existam planos para atingir G1, escolhe-se um novo objetivo a atingir, retornando ao passo A.

- Análise das ações no plano: uma vez escolhido um plano, $\mathrm{Ag} 1$ analisa a sua situação de objetivo quanto a G1, dependendo se a situação for do tipo autônoma ou dependente. 
Caso a situação seja autônoma, Ag1 é considerado autônomo para realizar aquele objetivo e assim não necessita da cooperação de nenhum outro agente. Neste contexto, Ag1 pode iniciar suas atividades para atingir o seu objetivo G1 sem a necessidade de formar coalisão. Na situação de dependência, entretanto, o Ag1 não pode iniciar imediatamente a execução do seu plano, pois primeiro precisa encontrar um agente que realize a ação que ele não sabe executar.

- Escolha do parceiro: através do mecanismo de resolução social, Ag1 calcula as suas relações e situações de dependência com os outros agentes relativos a G1 e, através do critério pré-estabelecido, escolhe-se os melhores possíveis parceiros. Caso não existam possíveis parceiros para a ação em questão, Ag1 escolhe um novo plano para atingir G1 retornando ao passo $\mathrm{B}$.

- Formação de coalisão entre os agentes: uma vez escolhido o melhor parceiro possível, aqui chamado de Ag2, Ag1 lhe enviará uma proposta de coalisão, que pode ter as seguintes propostas:

- Ag2 aceita a proposta e a coalisão é formada. A partir desse momento, iniciam-se os trabalhos para resolver G1. Ao fim desse processo, se as ações foram realizadas corretamente, G1 é dado como concluído e Ag1 pode retornar ao passo $\mathrm{A}$.

- Ag2 recusa a proposta e neste caso Ag1 tenta respectivamente encontrar outro parceiro, retornando ao passo D.

A recusa da proposta por $\mathrm{Ag} 2$ pode ocorrer pelos seguintes fatores:

- Ag1 inferiu uma conclusão errada a respeito de Ag2, provavelmente por ter informações incorretas ou incompletas sobre Ag2. Neste caso, Ag2 informa a $\mathrm{Ag} 1$ tais informações, e $\mathrm{Ag} 1$ pode realizar uma revisão de suas crenças sobre Ag2.

- Ag2 não considerou a proposta interessante para os seus objetivos.

Na Tabela 2 são apresentadas algumas características do modelo em questão aplicado no desenvolvimento do SMA da CV-Muzar na criação de sub-comunidades.

Tabela 2 - Características do modelo CBD

\begin{tabular}{l|l}
\hline \multicolumn{1}{c|}{ Situação } & \multicolumn{1}{c}{ Modelo CBD } \\
\hline Entrada de agentes na sociedade & Afeta a sociedade, pois há a necessidade da apresentação. \\
\hline Saída de agents da sociedade & $\begin{array}{l}\text { Afeta a sociedade, pois há a necessidade de avisar a todos os } \\
\text { agentes sobre a saída. }\end{array}$ \\
\hline Mais de um possível parceiro & $\begin{array}{l}\text { Enquanto há recusa por parte dos possíveis parceiros, a } \\
\text { comunicação continua. }\end{array}$ \\
\hline Encontrou parceiro ideal & $\begin{array}{l}\text { Ao analisar os prováveis parceiros, encontra o parceiro que pode } \\
\text { ajudá-lo com mais eficiência e este aceita ajudá-lo. }\end{array}$ \\
\hline $\begin{array}{l}\text { Dentre os possíveis parceiros, não } \\
\text { encontrou algum que aceitasse a } \\
\text { proposta }\end{array}$ & $\begin{array}{l}\text { É considerado o pior caso, pois todos os possíveis parceiros } \\
\text { recusam a proposta. }\end{array}$ \\
\hline
\end{tabular}

V. 6 № 1, Julho, 2008 
Não há parceiro que saibam realizar a ação

O agente ativo é autônomo ou não possui objetivos

O primeiro possível parceiro da lista aceita a proposta
Não há troca de mensagens desde que o agente ativo tenha as informações corretas a respeito dos demais membros da sociedade.

Não há procura por parceiros.

É considerado o melhor caso, pois as mensagens trocadas são uma proposta, um aceite e uma coalisão.

A Figura 5 apresenta os agentes ativos na sociedade SIP e a execução de envio das mensagens.

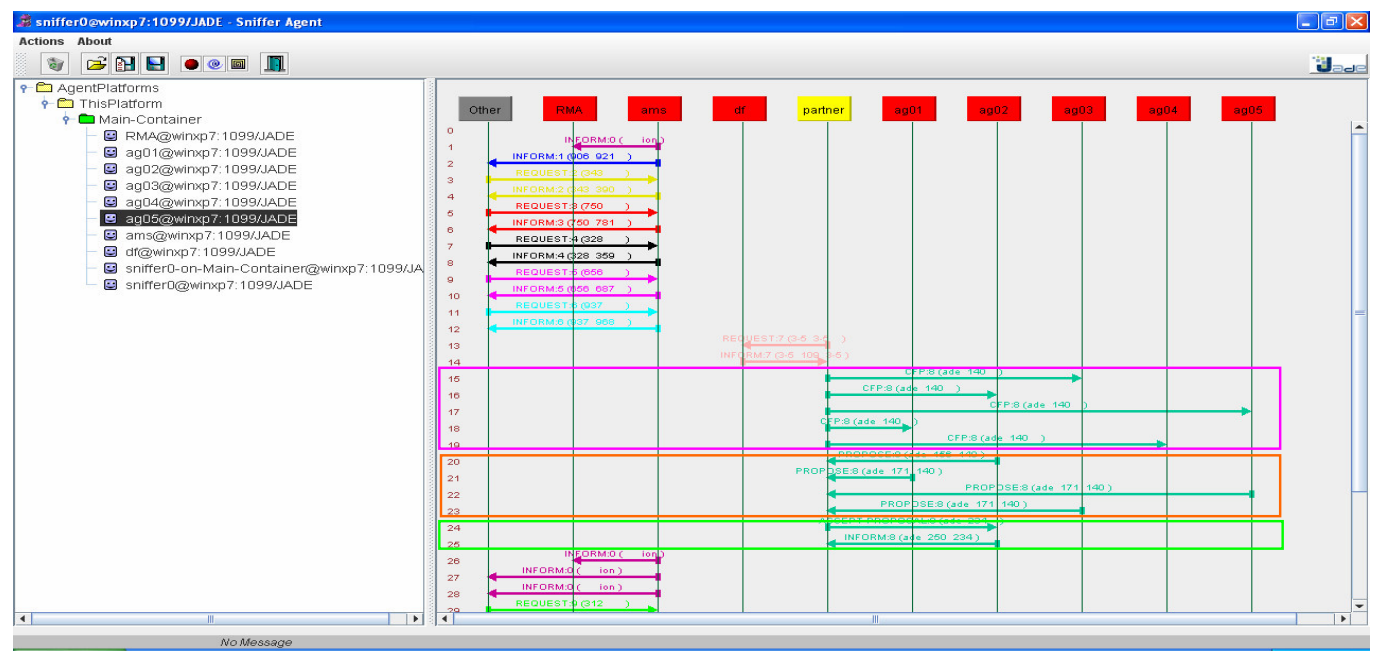

Figura 5. Comunicação entre os agentes na sociedade SIP

Na CV-Muzar a busca dos participantes fica toda sob responsabilidade do SMA. $\mathrm{O}$ coordenador da sub-comunidade não precisa se preocupar em encontrar parceiros para o seu grupo. Ele se concentra em animar o grupo e incentivar a criação de discussões que venham enriquecer o conhecimento. A Figura 6 ilustra o envio de um convite ao participante que possui perfil semelhante ao do grupo "Poluição da Água". Fica a cargo do participante receptor da mensagem decidir pela sua integração ou não no grupo.

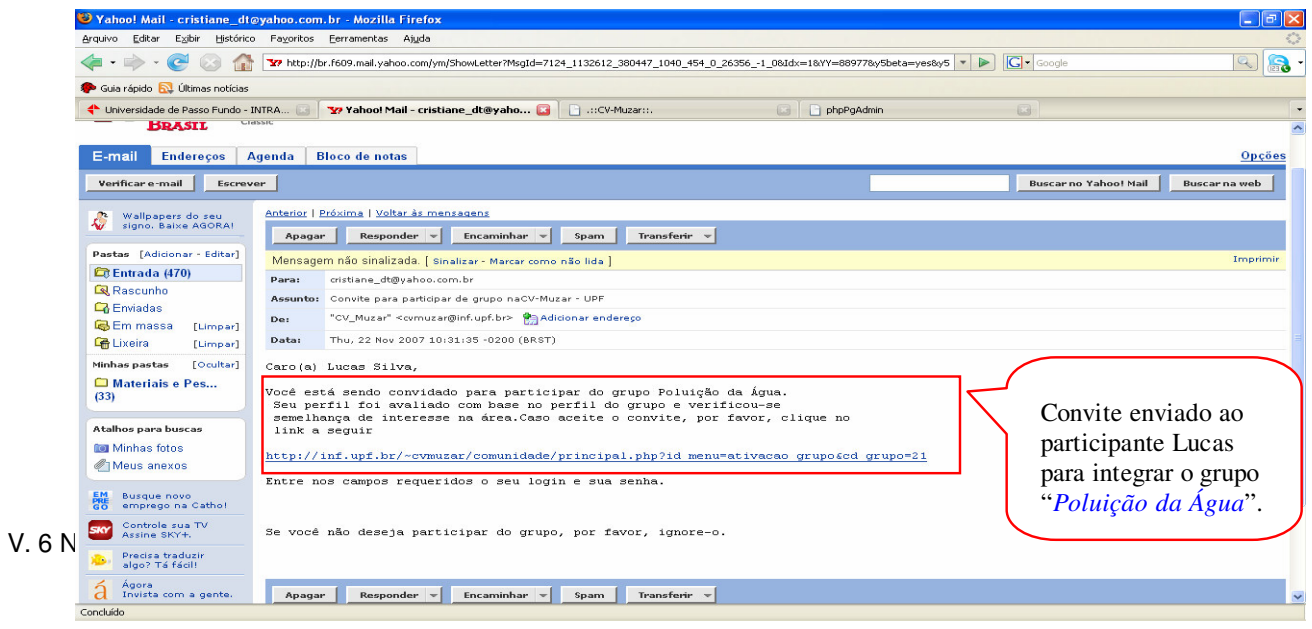


Figura 6. Exemplo de convite enviado pelo SMA aos participantes

\section{Ferramentas utilizadas para o Desenvolvimento}

O ambiente CV-Muzar foi desenvolvido utilizando Php 4.0, Ajax e banco de dados PostgreSQL 3.4.1. Todavia para o desenvolvimento das sub-comunidades optamos por utilizar a linguagem de programação JAVA por se tratar de uma linguagem que possui diversos mecanismos nativos que simplificam a programação de SMA, como por exemplo, concorrência e a comunicação entre objetos.

Para o desenvolvimento do SMA optamos por utilizar Jade (Jade Agent DEvelopment framework). Jade é um ambiente para desenvolvimento de aplicações baseada em agentes conforme as especificações da FIPA (Fundation for Intelligente Physical Agents) para interoperabilidade entre sistemas multiagentes totalmente implementado em Java. O Jade visa simplificar e facilitar o desenvolvimento de SMA, garantindo um padrão de interoperabilidade entre SMA através de um abrangente conjunto de agentes de serviços de sistema, os quais tanto facilitam como possibilitam a comunicação entre agentes, de acordo com as especificações da FIPA. Dentre os serviços podemos citar: serviço de nome (naming service) e páginas amarelas (yellowpage service), transporte de mensagens, serviços e codificação e decodificação de mensagens e uma biblioteca de protocolos de interação (padrão FIPA) pronta para ser usada. Toda a comunicação entre agentes é feita via troca de mensagens. Além disso, trabalha com todos os aspectos que não fazem parte do agente em si e que são independentes das aplicações, tais como transporte de mensagens, codificações e interpretação de mensagens e ciclo de vida dos agentes.

\section{Considerações Finais}

Neste trabalho foi utilizado o conceito de grupos para a formação de sub-comunidades na CV-Muzar. Como a CV-Muzar trata-se de um ambiente informal de aprendizagem, toda a caracterização por participantes e grupos ficou por conta de perfis e na semelhança de interesses e complementaridade de conhecimento para um bom desempenho do grupo.

Outro ponto relevante foi à escolha da tecnologia utilizada para o desenvolvimento dos grupos - os agentes inteligentes. A principal razão da utilização dessa tecnologia se dá pelo fato de ser uma tecnologia em expansão e de fácil adaptação às necessidades do ambiente.

Já o modelo de Coalisões Baseadas em Dependência foi escolhido pelo fato que se um agente não for totalmente autônomo para realizar as tarefas propostas, este pode tentar formar parceria para atingir seus objetivos. 
Com o encerramento dessa etapa de desenvolvimento, pretendemos analisar toda a parte de comunicações entre os agentes e traçar pontos críticos de comunicação que podem ser melhoras com o aprimoramento do desenvolvimento.

Por fim, com a possibilidade dos participantes formarem grupos menores de discussão acentua-se a possibilidade das comunidades virtuais serem, a cada dia que passa, ainda mais utilizadas no apoio ao ensino à distância informal, facilitando a comunicação e aproximando os participantes. A informalidade aqui mencionada referese, exclusivamente, ao fato de que a CV-Muzar foi desenvolvida para uma aprendizagem informal continuada, ao longo da vida.

\section{Agradecimentos}

Ao Conselho Nacional de Desenvolvimento Científico e Tecnológico pelo apoio através do Edital MCT/CNPq 15/2007 - Universal.

\section{Referências}

Barker T., Barker J. How Group Working Was Used to Provide a Constructive computer-Based Learning Environment. In: The Fourth International Conference on Cognitive Technology, University of Warwick, United Kingdom: 2001. p. 203.

De Marchi A. C. B. Um ambiente de suporte a comunidades virtuais baseados em repositório de objetos de aprendizagem informal em museus. 2005. Porto Alegre: PGIE/UFRGS, 2005. Tese de Doutorado.

Sichman, J.S. Raciocínio Social e Organizacional em Sistemas Multiagentes: avanços e perspectivas. São Paulo: USP, 2003. Tese (Escola Politécnica da Universiade de São Paulo, para obtenção do título de Professor Livre Docente)

Vygotsky, L. S. . The Collected Works of L.S.Vygotsky. v. 1. New York: Plenum Press, 1987.

Testa, C.D., De Marchi, A.C.B. Formando Sub-Comunidades na CV-Muzar com o Uso de Sistemas Multigentes. In: IX Simpósio Internacional de Informática Educativa, Universidade do Porto. Portugal

Wooldridge, Michael. Introduction to MuliAgent Systems. Editora Wiley 2002. 